\title{
A thousand years of pulmonary medicine: good news and bad
}

\author{
J.F. Murray
}

I should like to start by thanking Professor Gibson and all members of the Programme Committee for asking me to give this Millennial Lecture. I am, of course, greatly honoured at having been chosen for this, a once every one-thousand years event. One of the things Professor Gibson refrained from saying in his overly flattering introduction is that I actually started my medical career back in the first half of the last century, a long time ago. So I have been witness to over 50 years of medical progress - and what a half century it has been! But that is not what I am going to talk about.

What I propose to do this morning is, first of all, to discuss briefly some of the remarkable achievements in pulmonary medicine and the men and women who made them during the recently departed millennium. Consequently, I will start my review in the year 1000. Then, I will reflect on the evolution and present deplorable status of two of mankind's deadliest scourges, both of them chiefly pulmonary disorders, one practically as old as human beings themselves, and the other practically brand new. And finally, I will make some suggestions as to how the members of the societies that are sponsoring this World Congress on Lung Health can help solve a few of the existing problems. May I remind you that as the title of my talk indicates, I bring you both good news and bad news.

\section{The year 1000}

The year 1000 marked the end in Europe of the formless Dark Ages and the beginning of the slightly more progressive Medieval Period; culture and enlightenment were considerably more advanced in Asia at the time. There isn't much information available about ordinary life in Europe in the year 1000, but it has been characterized as "unimaginably mean, dirty, unhealthy, and short" [1].

Life expectancy averaged around 30 years, except for the few privileged people at the pinnacle of society, and even for them, survival past 50 years was uncommon. Infant mortality was a colossal $40 \%$; nutrition was inadequate, and hygiene was nonexistent. Infectious diseases abounded: measles, typhus, malaria, leprosy, and, of course, tuberculosis.

There was no organized medicine, and those few medical facilities that did exist were confined to palaces

Correspondence: J.F. Murray, International Union Against Tuberculosis and Lung Disease, 68 Boulevard Saint Michel, 75006 Paris, France. Fax: 33143299087 and monasteries. Medical care, if it can be dignified as such, was restricted to the nobility and clergy.

It is interesting to note that the world's population in the year 1000 was only around 400 million people and that the number of inhabitants increased very slowly during the next 750 years (fig. 1). In 1900 the global population remained well below 2 billion but then it increased dramatically during the last century to its present size of over 6 billion [2]. The recent population explosion pertains to another point I will make later on.

\section{From 1000 to 1543}

During the first half of the millennium, some notable events occurred that affected how medicine was taught and practised, and which diseases were endemic. Again, I am focusing on what took place in Europe, not Asia.

The first crusade began in the year 1099. Coincident with the movement of soldiers and other people, and perhaps attributable to it, there was an expansion of hospitals and other medical facilities. In 1100, the first European university was founded in Bologna. One hundred years later, there were new universities in Paris and Oxford, and, soon after, in many other cities. Medical schools and centres of medical expertise and education soon followed.

During the 13th century, leprosy spread widely throughout Europe. From 1347 to 1349, the world was ravaged by the first pandemic of bubonic plague, which started in Asia, where it killed millions of people,

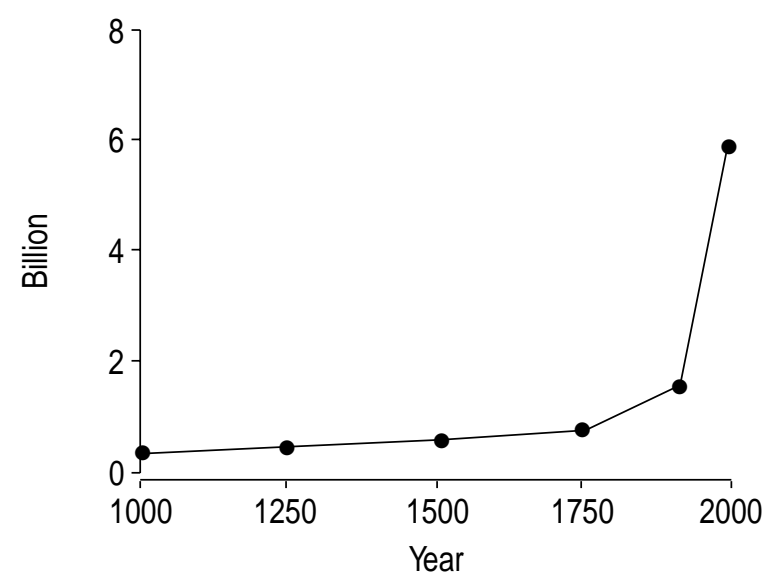

Fig. 1. - Estimates of the world's population from the year 1000 to the year 2000 showing the dramatic increase, more than tripling, during the last century. Data from [2]. 
and which then spread to Europe, where it wiped out one-quarter to one-third of the entire population. Beginning in about 1500, upon the return of explorers from the New World, an apparently particularly virulent form of syphilis unfolded and extended throughout the Old World.

\section{From 1543 to 1799}

Many experts believe that modern medicine began in 1543 with the publication of De Humani Corporis Fabrica by Andreas Vesalius (fig. 2). Vesalius introduced the science of meticulous observation and accurate description in the form of exquisitely detailed anatomic plates, which were designed and executed in the studio of the great Italian artist Titian. Vesalius paid much more attention to the skeleton and muscles of the body, which dominate his illustration portfolios. Figure 3 is a reproduction of the only plate of his I could find that shows the heart and great vessels, flanked by a pair of unhealthy-looking collapsed lungs.

It is well established that Vesalius was familiar with the precepts of Galen, which had dominated both the conceptual thinking and the practice of medicine for over 1,000 years. So we are reasonably sure that Vesalius was well aware that his precise anatomic observations in De Fabrica contradicted many of Galen's cherished tenets. Nevertheless, Vesalius seems to have been totally unprepared for the furious reaction

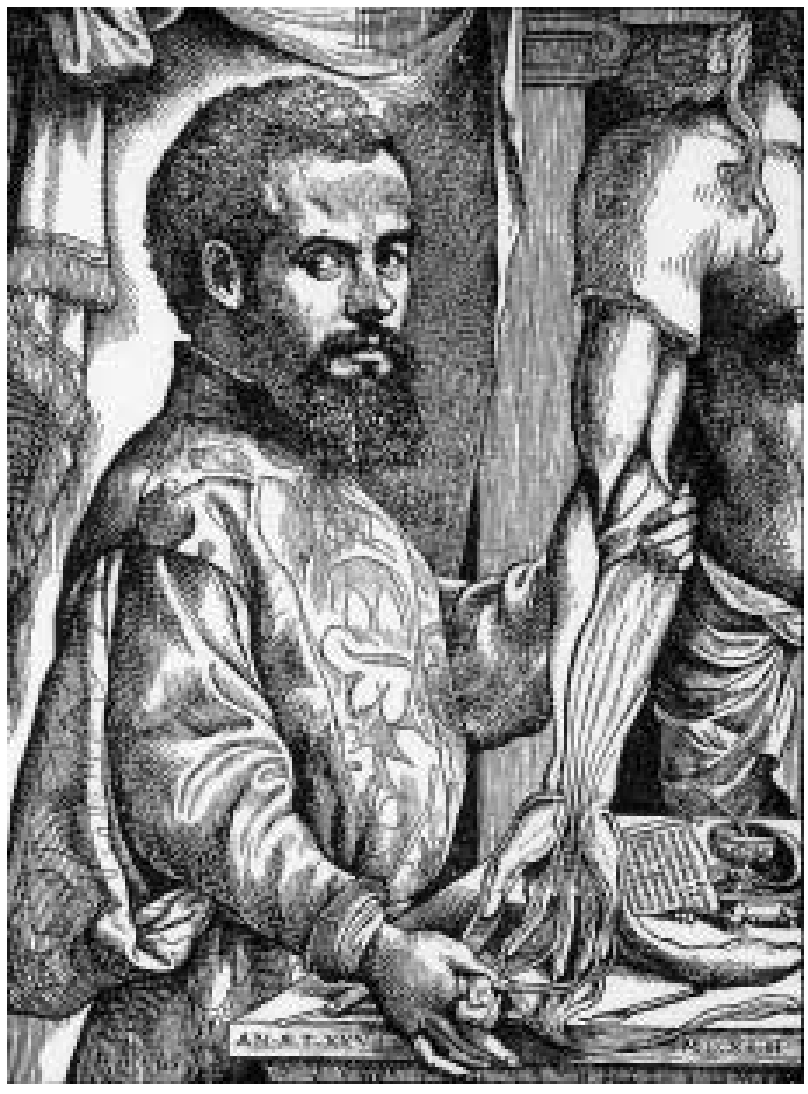

Fig. 2. - Andreas Vesalius (1514-1564) as depicted in one of the plates from his masterpiece De Humani Corporis Fabrica.

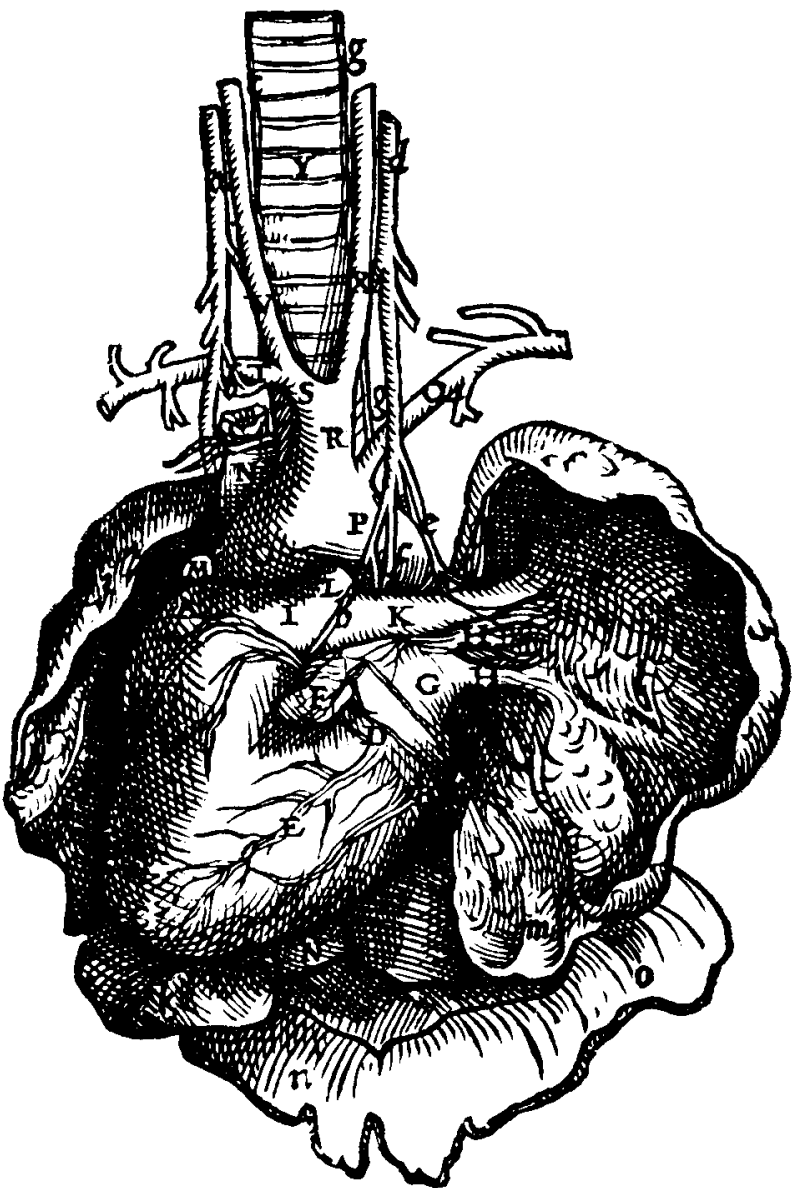

Fig. 3. - View of the heart, lungs, great vessels, and recurrent laryngeal nerves from one of the anatomical plates in Vesalius De Humani Corporis Fabrica.

and violent repudiation of his masterpiece. In a fit of rage and disappointment, he burned all his manuscripts and left Padua, never to do original anatomic studies again [3].

The next person to refute Galen and regret it was Michael Servetus, who had worked in Paris with Vesalius, both as prosectors in anatomy, before Servetus became a theologian. Galen believed that blood "sweated" from the right ventricle to the left ventricle through invisible pores in the interventricular septum. Servetus correctly stated that blood flowed from one ventricle to the other through the lungs. Shortly after publishing this heresy, John Calvin had Servetus burned at the stake, less for contradicting Galen than for his revisionist unitarian religious views.

We know now, that Ibn Nafis, a Damascus physician, clearly described the flow of blood through the lungs in the thirteenth century, 400 years ahead of Servetus; this account, however, was not known to the Western world until it was discovered by an Egyptian medical student in 1922 [4].

A complete description of the circulation, including blood flow through the lungs, was finally published in 1628 by William Harvey, who delayed publication of his findings for 16 years, in part because of Servetus' fate and the dangers of overturning established dogma. 
Harvey, though, was rewarded for his discovery by becoming physician to King Charles I of England.

Harvey established the basic principles of the circulation of blood in the early-seventeenth century. Knowledge about the physiology of respiration and the importance of oxygen, however, lagged almost a century and a half behind. A start was made by Joseph Priestly, who discovered the presence of oxygen in air, but Priestley hadn't the faintest idea about its chemical and physiologic importance. It was Antoine Lavoisier, who named Priestley's gas oxygen and defined its role in combustion, chemical reactions, and respiration. Though probably France's greatest chemist ever, Lavoisier lost his head to the guillotine during the French revolution. (Although the making of new scientific discoveries was not without considerable risk in those days, Lavoisier was executed because of his contrary political beliefs; Servetus, too, was condemned largely because of his heretical religious views.)

\section{From 1800 to 1999}

René Laënnec (fig. 4) is considered by many to be the Father of Pulmonary Medicine owing to his invention

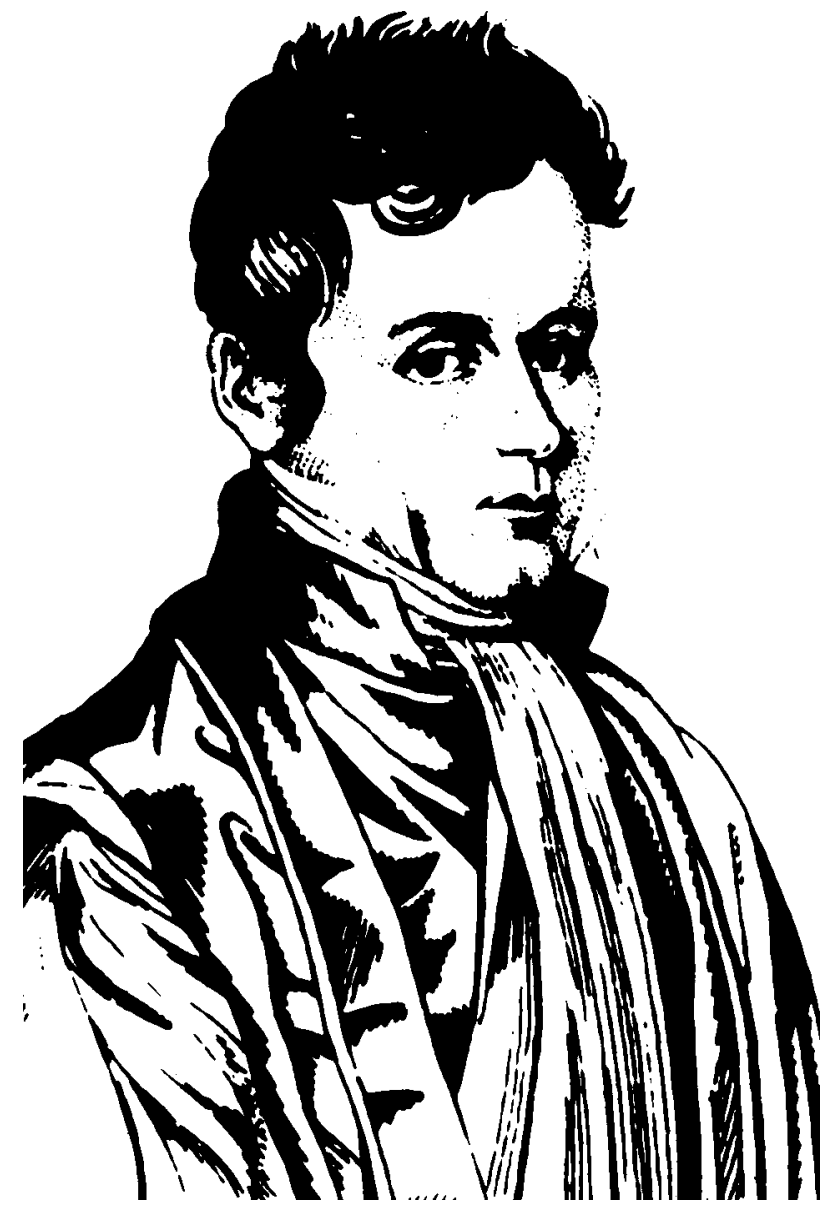

Fig. 4. - Portrait of René T. H. Laënnec (1781-1826) at about the time he published his treatise on acuscultation (1819). Published by permission of the New York Academy of Medicine library. of the stethoscope, and his brilliant description and classification of the sounds he heard when listening to normal and diseased lungs [5]. Importantly also, in 1804, he reasoned, from observations made at hundreds of autopsy examinations, that the many different pathological manifestations of tuberculosis all belonged to one and the same disease that he called by one of its old names, phthisis: a brilliant deduction. Tragically, he, too, died of tuberculosis in 1826 when only 45 years old.

Now we move on another 50 years to the advent of the science of bacteriology, which was founded by the great Louis Pasteur who became famous in 1859 for demolishing the theory of spontaneous generation. Pasteur then went on to establish the role of microorganisms in fermentation, save the French wine industry, and prepare the first vaccine. Pasteur recognized and praised the talents of Robert Koch (fig. 5), who was the first person to isolate a bacterium, Bacillus anthracis, in pure culture. Koch more than exceeded Pasteur's advance promotion when in 1882, he announced his monumental discovery of Mycobacterium tuberculosis, the cause of mankind's greatest scourge ever, and he enunciated Koch's postulates, the enduring criteria for establishing the cause of an infectious disease.

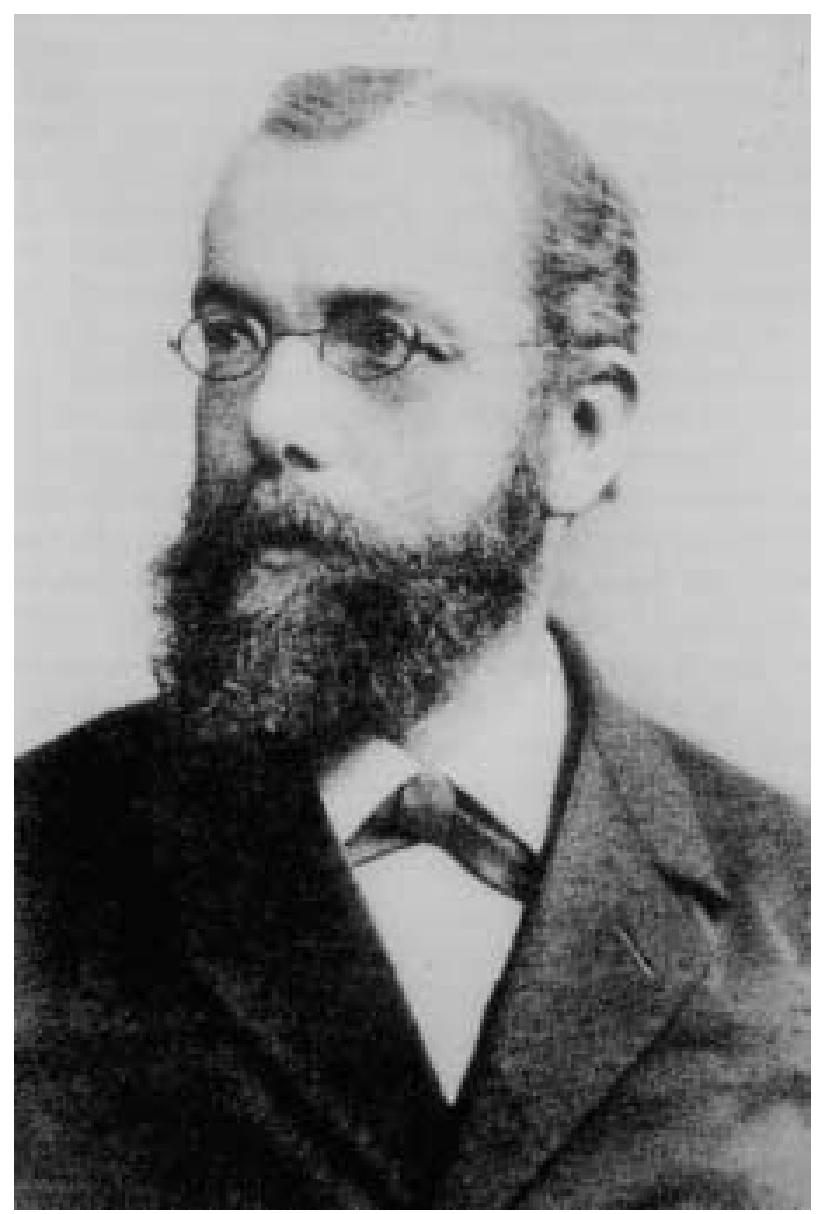

Fig. 5. - Photograph of Robert Koch (1843-1910) probably taken not long after he gained fame for his monumental discovery of Mycobacterium tuberculosis (1882). 
Not long afterward, Wilhelm Konrad Röntgen discovered X-rays and took the first röntgenograms. Within only a few years, the apparatus was greatly improved and the technique was used to diagnose tuberculosis and other lung diseases.

\section{Chemotherapy}

Koch's discovery of the causative bacillus and Röntgen's discovery of X-rays paved the way for an accurate diagnosis of tuberculosis and documentation of its pulmonary manifestations, but there was no way to stop the disease from killing its victims. The long sought-after cure for tuberculosis and other infectious diseases began with Paul Ehrlich, a disciple of Koch's, who invented the concept of chemotherapy, the administration of an artificial chemical substance to treat a disease. After arduous experiments with 605 different compounds, each of which failed, the 606th succeeded. In 1905, Ehrlich discovered the "magic bullet", the first antimicrobial agent, Salvarsan, which was able to cure syphilis.

Twenty years later, Gerhard Domagk invented Prontosil, the progenitor of sulphur drugs, still a staple in clinical medicine. About the same time, Alexander Flemming discovered penicillin, though it was not available for clinical use until 1944, shortly after René Dubos had discovered tyrothricin, the first antibiotic produced by bacilli that inhabit the soil. This galvanized further studies of soil microbes by Selman Waksman that led, five years later, to the discovery of streptomycin, the first truly effective antimicrobial agent against tuberculosis. All of these giants except Dubos received Nobel Prizes, and their heroic efforts are nicely recounted by Ryan [6] in his book, The Forgotten Plague. How the Battle Against Tuberculosis Was Won - and Lost.

\section{Respiratory physiology}

By the beginning of the Nineteenth century, the exchange of oxygen and carbon dioxide was known to occur in the lungs, but progress in respiratory physiology was slowed by the 50-year controversy over whether oxygen was exchanged between alveolar gas and pulmonary capillary blood by active secretion or by simple diffusion. In 1910, the argument was settled, definitively, in favour of diffusion by August and Marie Krogh in a now-classic series of publications. An excellent summary of the evolution of knowledge concerning the entire field of respiratory physiology and the people who contributed to the progress can be found in the recent book by WEST [7], Respiratory Physiology. People and Ideas.

The accumulating knowledge about pulmonary gas exchange and lung mechanics was put to clinical use in 1952 by Bjorn Ibsen who created the first Intensive Care Unit in the world in Copenhagen to treat victims of the last great worldwide epidemic of poliomyelitis [8]. Ibsen's approach incorporated a tracheotomy and an endotracheal tube, through which teams of medical students would pump oxygen-enriched air by squeezing a recoiling bag into polio victims' lungs as long as they couldn't breathe by themselves, sometimes for 2 or 3 months.

\section{Mistakes}

Apart from the occasional breakthrough, progress in pulmonary medicine during the millennium was made mainly in hesitant incremental steps punctuated by intermissions and occasional setbacks. One of the latter occurred in 1930, in Lübeck, Germany, where 249 babies who were supposed to be vaccinated with protective Bacille Calmette-Guérin (BCG), an attenuated strain of Mycobacterium bovis, were instead injected with large numbers of living, virulent $M$. tuberculosis. Tragically, 76 babies died of progressive tuberculosis. Needless to say, this disaster had a chilling effect on the use of BCG, which was being highly touted and increasingly used at the time. There is, however, an interesting aside to this devastating accident that has been largely overlooked: the remaining 173 babies developed only minor lesions and 12 years later were alive and free of tuberculosis, thus demonstrating that even in immunoincompetent newborns, heavy inoculation with tubercle bacilli is by no means invariably fatal [9]. I like to view this remarkable outcome as yet another example of the magnificent survival skills of the human body, even a very immature one.

The spectacular advances that were being made in the latter half of the twentieth century led to some extraordinary predictions about the future of medicine that, when viewed in retrospect, proved to be incredibly shortsighted. One on these came from a National Institutes of Health-sponsored conference in 1966, which led to a new way of thinking about medical research: "most everything we need to know for the prevention and cure of disease is now known; all we must do now is apply it" [10]. It is interesting to note that just a few years ago, the Global TB Programme of WHO came out with exactly the same seductive (but erroneous) philosophy concerning the future control of tuberculosis in the world: all that was needed to solve the immense problem was to apply existing knowledge and available techniques.

In 1969, the Surgeon General of the United States, William H. Stewart, told the US Congress that it was time "to close the book on infectious diseases." This heady requiem, obviously, was delivered before the development of resistance to standard antimicrobial drugs by many common bacterial pathogens, and the discovery of new infectious agents, including the hanta virus, which has now been detected in 27 states and several countries, and, of course, the human immunodeficiency virus (HIV), which presently infects 34 million people in the world and has already caused the deaths of an additional 18 million [11].

\section{The year 2000}

Although many fundamental discoveries concerning anatomy and physiology were made during the sixteenth, seventeenth and eighteenth centuries, most 
of the scientific underpinnings of modern pulmonary medicine were established during the last 150 years, and it appears that the pace of development of new scientific achievements and their clinical applications has picked up. Table 1 lists some of the advances in the field of pulmonary medicine that have greatly enhanced our ability to diagnose lung diseases, and table 2 lists some of the advances in our ability to treat and prevent lung diseases. I won't go into detail about the individual components of these two tables, every chest physician is aware of them and their impact on the daily practice of pulmonary medicine. Suffice it to say that each of the improvements represents the collective efforts of numerous laboratory scientists and clinical investigators. I can underscore the rapid pace of these advances by affirming that when I started in medicine half-acentury ago, many of these modalities had not yet been discovered, and those that were available were in a primitive state.

\section{What next?}

No one alive in the year 1000 could conceivably have imagined the medical progress that I have just highlighted. For this reason, I am going to resist making predictions about what's in store during the coming millennium. But I do want to turn your attention to a closer examination of what in my opinion are the two most important problems in respiratory medicine in the world today: tuberculosis and the ravages of cigarette smoking. These are issues that all pulmonary physicians and persons concerned with lung health should know about and be prepared to deal with in the future.

\section{Tuberculosis}

The diagram in figure 6 , models the changes in the mortality rate, not incidence rate, in several Western European countries from 1750 to 1980 [12]. You can see that mortality reached its peak in about 1800 , when all

Table 1. - Pulmonary medicine in the year 2000: Improvements that have taken place in diagnostic methodologies

Inclusive microbiological techniques

Powerful imaging methods

Comprehensive physiological evaluation

Extensive array of biochemical studies

Improved methods of tissue sampling and pathological identification

Table 2. - Pulmonary medicine in the year 2000: Improvements that have taken place in armamentarium for prevention and treatment

Expanding array of preventive vaccines

Powerful antimicrobial agents

Potent antiinflammatory and immunosuppressive medications

Concepts of and facilities for intensive care

Advanced techniques of surgery and anesthesiology

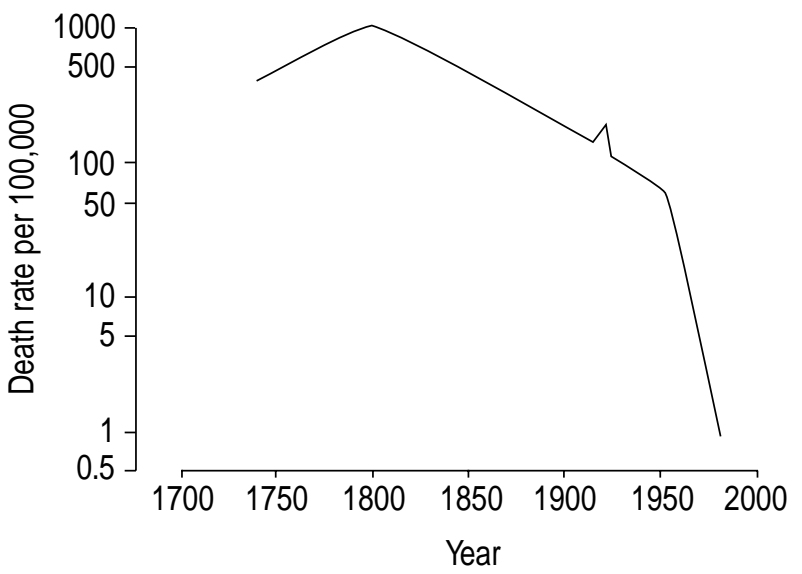

Fig. 6. - Illustration showing changes in the estimated mortality rate from tuberculosis in certain developed countries in Western Europe 1750-1980. Diagram modified and reprinted with permission from [12].

of the deplorable socioeconomic features of the evolving industrial revolution were at their worst. A mortality rate of 1000 per 100,000 in 1800 means that $1 \%$ of all living people died of tuberculosis that year. Another fact that expresses the gigantic toll from tuberculosis during that period is that $25 \%$ of all deaths were attributed to the disease.

I have already mentioned the important discoveries of $M$. tuberculosis by Koch and of X-rays by Röntgen. These and subsequent milestones in our ability to manage tuberculosis are listed in table 3. Because of these and many other accomplishments, by the 1960s and 1970s, tuberculosis became relatively easy to diagnose and to treat; almost everyone who is properly treated can be cured; and it is even possible to prevent tuberculosis from occurring. CoLE et al.'s [13] recent unravelling of the genome of $M$. tuberculosis opens the way for genetically targeted vaccines, specific techniques for detecting active and latent infection, and designer-fashioned antituberculosis drugs.

Figure 6, though accurate, is deceptive. It illustrates the events in Western Europe and North America, places where deaths from tuberculosis have been steadily declining, but it leaves out all the rest of the world, including the so-called developing countries,

Table 3.-Historic milestones and the people who made them that have contributed to the ability to diagnose, cure, and prevent tuberculosis in the year 2000

\begin{tabular}{ll}
\hline 1882 & $\begin{array}{l}\text { Koch - identification of Mycobacterium } \\
\text { tuberculosis }\end{array}$ \\
1895 & $\begin{array}{l}\text { Röntgen - discovery of X-rays and } \\
\text { röntgenography }\end{array}$ \\
1921 & $\begin{array}{l}\text { Calmette and Guérin - development of } \\
\text { BCG vaccine }\end{array}$ \\
1944 & $\begin{array}{l}\text { Hinshaw and Feldman - effectiveness of } \\
\text { streptomycin }\end{array}$ \\
1957 & $\begin{array}{l}\text { Ferebee - effectiveness of isoniazid chemo- } \\
\text { prophylaxis } \\
\text { Cole - Description of genome of } M . \\
\text { tuberculosis }\end{array}$ \\
\hline
\end{tabular}

BCG: Bacille Calmette-Guérin. 
where $86 \%$ of the world's population live, and where $95 \%$ of all new cases of tuberculosis and $98 \%$ of its deaths occur. Moreover, tuberculosis has been worsening in resource-poor countries, a trend that is expected to continue, for the reasons listed in table 4. An exaggerated reality of the worldwide catastrophe is shown in the worst-case scenario (fig. 7) published just a few years ago by WHO [14], but recently ammended [15]. I suspect the global tuberculosis situation will continue to deteriorate, at least for awhile, because it has proven immensely difficult to contain the disease in the face of a high prevalence of HIV infection, even in countries that have good tuberculosis control programmes [16]. So as long as HIV continues to propagate in places where as many as half the adults are already infected with tubercle bacilli, tuberculosis will remain a serious global problem.

\section{Smoking}

Let us turn now briefly, from the world's oldest and probably greatest killer, tuberculosis, which has been a scourge of mankind practically from the time human beings appeared on this planet, to the newest scourge, tobacco smoking, which really only declared itself during the last 50 years. Figure 8 reproduces World Bank and WHO estimates of the cumulative worldwide deaths from cigarette smoking, at 25-year intervals, beginning in 1950 and extending through 2050 [17]. You can see that during this 100 -year period, which we

Table 4.-Reasons for the resurgence of tuberculosis in the year 2000

Growth of world's population (see fig. 1)

Catalytic effect of HIV infection and its spread

Poor to absent control programmes

Increasing drug resistance

Lack of political will and necessary resources

HIV: human immunodeficiency virus.

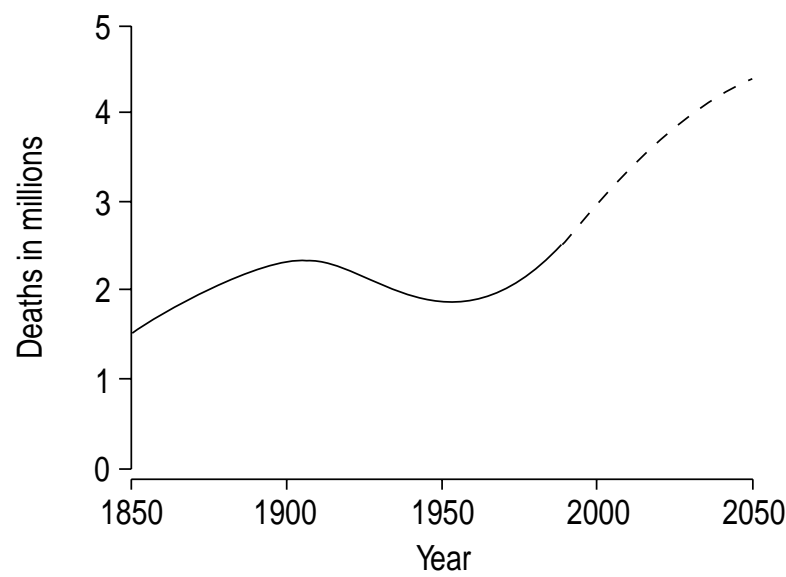

Fig. 7. - Worst-case estimates by TB/WHO of past (-) and future (- -) number of annual deaths worldwide from tuberculosis. Modified from [14].

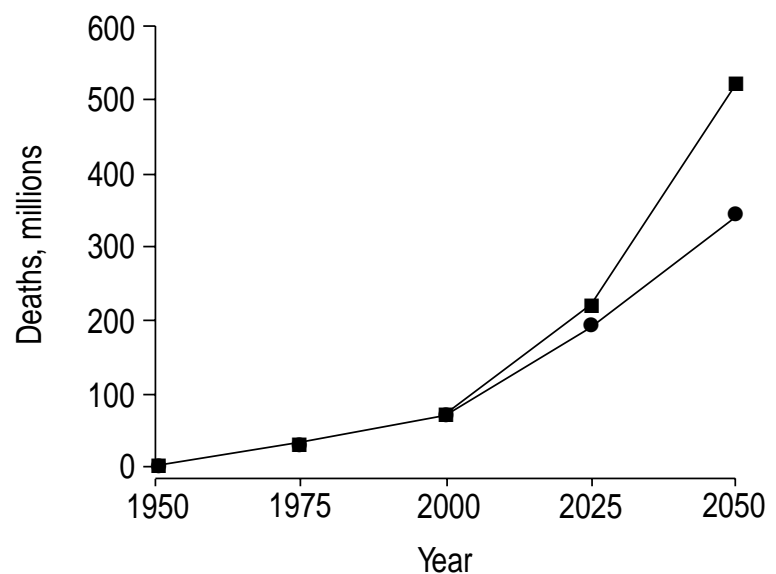

Fig. 8. - Graph showing estimates by the World Bank and WHO of the cumulative number of deaths worldwide related to the use of tobacco from 1950-2050. The lower line shows how the number would decrease if consumption by adults were to halve. Modified from [17].

are now in the middle of, the cumulative number of deaths is a staggering 520 million. Another way of expressing these gruesome statistics is to state that nearly half-a-billion people, most of whom are now alive, will die during the next 50 years if current smoking practices prevail; the lower line in the figure shows that the number would be reduced to 340 million if consumption by adults were to decrease by half.

Per capita cigarette consumption is decreasing in industrialized countries, but increasing in resource-poor countries and, accordingly, will increase throughout the world. At first glance, these trends do not appear particularly impressive, but when extrapolated a mere 30 years from now [18], the estimates are mind boggling. In the year 2030, tobacco smoking will kill 10 million persons per year and will be the largest single cause of death worldwide. At present, the pandemic of chronic disease and premature death from cigarette smoking affects chiefly people living in industrialized countries. In the year 2030 , by contrast, $70 \%$ of tobacco-related deaths will occur in low-income countries.

It is extremely instructive to consider the fundamental causes of deaths from tuberculosis on the one hand and deaths from tobacco smoking on the other. Deaths from tuberculosis are caused by the bacterium M. tuberculosis, a product of nature. Evil though it may be, it has no intelligence, and it infects and kills according to its own inherent biological imperatives, which can be attenuated or amplified by its hosts' defense mechanisms and by the prevailing socioeconomic conditions. Deaths from cigarette smoking, every single one, are caused by the tobacco industry, which in striking contrast to $M$. tuberculosis, is a creation of venal and reprehensible people. The industry is the deadly vector that is invading the developing world like a virulent infection. But unlike M. tuberculosis, cigarette manufacturers have brains and tremendous political clout backed up by enormous amounts of money. For decades, the industry spent millions and millions of dollars, each year, publicly 
denying that smoking tobacco caused lung cancer and other diseases and that nicotine was addictive. Now, the truth has leaked out in several rich countries where per capita cigarette consumption is beginning to decline; but this is more than made up for in low-income countries where industry-sponsored advertising deception prevails and political strong-arming guarantees expanding markets. Coercing people to use this certified lethal product remains immensely profitable.

\section{What to do}

The two leading causes of global pulmonary disease I chose to describe in some detail, tuberculosis and smoking, illustrate the prevailing disparity between rich and poor and how and why it is worsening. There are many other examples. These inequalities are not only shameful but morally unacceptable and need to be addressed by the people in this room and the organizations we belong to. And I believe there is something we can do about it. But to be maximally effective, we need to work together. I suggest we form a consortium of professional lung societies that are concerned with the preservation of World Lung Health. Imagine the collective clout that the ERS/ ATS/APSR/IUATLD, the societies that are sponsoring this World Conference on Lung Health, would have if the brain-power of their 20,000 or more members were wired together through the internet and thoughtfully organized to achieve common objectives. Owing to the widespread availability of email, this can easily be achieved.

Table 5 lists just a few of the things this powerful band of pulmonary brothers and sisters, professionals from over 100 countries, rich and poor, could accomplish. Supporting the "Stop TB Initiative" and encouraging the formation of "Smoke-Free Environments," a key way to make smoking socially unacceptable, one of the threats the tobacco industry fears most, are top priority undertakings. In addition, you should know that the first negotiating meeting of the Framework Convention on Tobacco Control will be held soon to determine the contents of an international treaty aimed at regulating the international tactics of the tobacco industry. Such a treaty will provide enormous help to individual governments by allowing them to withstand political and economic pressure from the industry. It is obviously important for all organizations that represent global lung health, including our professional societies, to champion a strong treaty.

Table 5.-Some activities that could be undertaken by a consortium of professional respiratory societies concerned with the preservation of world lung health

Educate the public and politicians about lung health Educate health professionals about good medical practices Join with and participate in the "Stop TB Initiative" Encourage "Smoke-Free Environments" Undertake vigorous advocacy activities

\section{Conclusion}

It is hard to compress the events of one thousand years into a balanced and inclusive talk. But it is safe to conclude that not much progress was made during the first five centuries of the last millennium, but thereafter, there was astounding scientific and clinical progress in medicine, including pulmonary medicine, that changed the way every human being on earth lives today. In the year 1000, medical care was largely unavailable and what there was may well have done more harm than good. Now, precise diagnosis of most illnesses is possible and specific treatment is available for the majority of them. Immunization and antimicrobials have tamed many of the infectious plagues of the past and life expectancy has lengthened enormously. But as I have emphasized, this progress has favoured the lives of a small fraction of the world's population a great deal more than it has improved the lives of the much larger remainder. One of the challenges for the millennium that is just beginning, clearly, is to correct this imbalance to ensure that all people share the benefits of contemporary medicine.

The great American pop artist Andy Warhol once proclaimed that every person would have his or her 15 minutes on a world's centre stage. Thanks, though, to Professor Gibson and his selection committee, and thanks to everyone here in the audience, I have had 45 minutes. And I am grateful to all of you for making it possible. Many thanks for listening to me.

\section{References}

1. Quotation from William McCarthy, Catholic University of America, In: International Herald Tribune, December 28, 1999, p. 1.

2. Historical estimates of world population. US Government website: www.census.gov/ipc/www/worldhis.htm/

3. Fulton JF. Vesalius Four Centuries Later. Lawrence, University of Kansas Press, 1950, pp. 1-52.

4. West JB. Pulmonary blood flow and gas exchange, In: West JB. ed. Respiratory Physiology. People and Ideas. American Physiological Society. New York, Oxford University Press, 1996, p. 142.

5. Laënnec RTH. De l'Auscultation Médiate, Paris, Brosson and Chaudé, 1819; English translation by Forbes JA. Treatise on Diseases of the Chest, London, Underwood, 1821; reprinted, New York, Hafner Publishing Company, 1962.

6. Ryan F. The Forgotten Plague. How the Battle Against Tuberculosis Was Won - and Lost, Little, Brown and Company, Boston, 1992, pp. 1-460.

7. West JB ed, Respiratory Physiology. People and Ideas. American Physiological Society. New York, Oxford University Press, 1996, 1-409.

8. Severinghaus JW, Astrup P, Murray JF. Blood gas analysis and critical care medicine. Am J Respir Crit Care Med 1998; 157: S114-122.

9. Dubos R, Dubos J. The White Plague. Tuberculosis, Man, and Society. Rutgers University Press, New Brunswick, NJ, 1952, pp. $122-123$.

10. Shannon JA. National Institutes of Health. Present and potential contribution to application of biomedical knowledge. Proceedings of Conference on Research 
in the Service of Man, Oklahoma City,October 24-27, 1966.

11. UNAIDS. Update on the global HIV/AIDS epidemic. UNAIDS website: www.unaids.org/epidemic_update/ report/Epi_report.htm

12. Murray JF. J. Burns Amberson Lecture. The white plague: down and out or up and coming? Am Rev Respir Dis 1989; 140: 1788 - 1795.

13. Cole ST, Brosch R, Parkhill J, et al. Deciphering the biology of Mycobacterium tuberculosis from the complete genome sequence. Nature 1998; 393: $537-$ 544.

14. WHO report on the tuberculosis epidemic, 1994. $\mathrm{WHO} / \mathrm{TB} / 94$
15. Dye C, Scheele S, Dolin P, et al. Global burden of tuberculosis: estimated incidence, prevalence, and mortality by country. WHO global Surveillance and Monitoring Project. JAMA 1999; 282: 677-686.

16. Murray JF. Tuberculosis and HIV infection: A global perspective. Respiration 1998; 65: 335-342.

17. Jha P, Chaloupka FJ. Curbing the Epidemic: Governments and the Economics of Tobacco Control. World Bank, Washington, DC 1999, pp. 80.

18. Jha P, Chaloupka FJ. Curbing the Epidemic: Governments and the Economics of Tobacco Control. World Bank, Washington D.C. 1999, pp. $22-23$. 